\title{
Changes in Cryphonectria parasitica Populations Affect Natural Biological Control of Chestnut Blight
}

\author{
Marin Ježić, Jelena Mlinarec, Rosemary Vuković, Zorana Katanić, Ljiljana Krstin, Lucija Nuskern, Igor Poljak, \\ Marilena Idžojtić, Mirta Tkalec, and Mirna Ćurković-Perica ${ }^{\dagger}$
}

First, second, sixth, and tenth authors: University of Zagreb, Faculty of Science, Department of Biology, Division of Microbiology, Marulicev trg 9a, Zagreb, Croatia; third, fourth, and fifth authors: J. J. Strossmayer University of Osijek, Department of Biology, Cara Hadrijana 8A, Osijek, Croatia; seventh and eighth authors: University of Zagreb, Faculty of Forestry, Department of forest genetics and dendrology, Svetosimunska 25, Zagreb, Croatia; and ninth author: University of Zagreb, Faculty of Science, Department of Biology, Division of Botany, Rooseveltov trg 6, Zagreb, Croatia.

Accepted for publication 12 February 2018.

\begin{abstract}
Invasive species, especially plant pathogens, have a potential to completely eradicate native plant species and remodel landscapes. Tripartite interactions among sweet chestnut (Castanea sativa), chestnut blightcausing invasive fungus Cryphonectria parasitica, and hyperparasitic virus Cryphonectria hypovirus 1 (CHV1) were studied in two populations. The number of different vegetative compatibility (vc) types of $C$. parasitica more than doubled over the 10 years, while the hypovirulence incidence dropped in one population and slightly increased in the other one. Over the course of our 3-year monitoring experiment, the prevalence of hypovirulent isolates obtained from monitored cankers increased slowly (i.e., more

hypovirulent isolates were being obtained from the same cankers over time). Within studied cankers, considerable changes in vc type and CHV1 presence were observed, indicating a highly dynamic system in which virulent and hypovirulent mycelia, sometimes of discordant vc types, often appeared together. The increase in hypovirulence prevalence did not have any observable curative effect on the cankers and, occasionally, reactivation of healed cankers by new, virulent $C$. parasitica isolates was observed. Both short- and long-term observations and revalidation of the infected plant populations are necessary to accurately estimate disease progress and formulate an adequate disease management strategy.
\end{abstract}

Although exotic invasive species are generally not considered dangerous enough to outcompete the native ones to the verge of extinction, some invasive pests and pathogens are an exception and clearly pose a threat to the native biota (Davis 2003; Gurevitch and Padilla 2004). Fungal pathogens are of particular interest, because they have been responsible for the decline of many different plant and animal species and are known to spread globally with the aid of human transportation (Fisher et al. 2012). Two important plant diseases caused by fungi occurred during the 20th century: the spread of Ophiostoma novo-ulmi, which transformed the landscapes of Europe (Brasier and Buck 2001), and the introduction of Cryphonectria parasitica into North America and Europe, causing massive damage to chestnut forests (Anagnostakis 1987; Robin and Heiniger 2001). Aside from diseases, pressure from invasive species and climate change have been suggested as among the most important stress factors affecting forest health (Trumbore et al. 2015).

Considering plant pathogens, spatial differences in the population structure have been researched extensively, whereas the temporal changes have always been somewhat neglected (Houston 1994; McDonald and Linde 2002; Penczykowski et al. 2016). Furthermore, most research has been done on annual crops and their pathogens, because the rapid disease cycle enables researchers to quickly assess population changes (Atallah et al. 2004; Naegele

†Corresponding author: M. Ćurković-Perica;

E-mail: mirna.curkovic-perica@biol.pmf.hr

Funding: This study was funded by Croatian Science Foundation (Hrvatska Zaklada za Znanost), project number 5381 and Schweizerischer Nationalfonds zur Förderung der Wissenschaftlichen Forschung, SCOPES project number IZ73Z0_152525/1.

(C) 2018 The American Phytopathological Society et al. 2016). In those populations, changes in virulence (for pathogens) and resistance (for hosts) can occur rather quickly (Thrall and Burdon 2003) because they have an opportunity to modify, mutate, or recombine their resistance genes at least once a year. This way, pathogens can direct the evolution of their hosts within a few generations, facilitating research on these systems (Penczykowski et al. 2016). Changes in population structure over longer time periods have been investigated only occasionally in both annual crops pathogens (Thach et al. 2016) and forest pathogens (Brasier et al. 2004; Springer et al. 2013). Generally, however, researchers are confronted with either old, postepidemic populations with high pathogen diversity (Solla et al. 2008) or new, mostly clonal populations (Gross et al. 2014; Milgroom et al. 2008) and rarely revisit pathogen populations to reassess the situation in the field. The European sweet chestnut, Castanea sativa, has been significantly impacted by an introduced pathogenic fungus, Cryphonectria parasitica, since the middle of 20th century (Biraghi 1946). Today, most of the European forests are infected and C. parasitica is well established throughout the sweet chestnut range (Robin and Heiniger 2001). The genetic and genotypic diversity, as well as gene and genotype flow of $C$. parasitica populations in Europe, have been studied thoroughly in many different countries (Ježić et al. 2012; Krstin et al. 2011; Milgroom et al. 2008; Peters et al. 2014; Robin et al. 2000). Furthermore, it is known that $C$. parasitica has a mixed mating system, spreading to new areas clonally (Milgroom et al. 2008). In older populations, sexual reproduction occurs as well (Dutech et al. 2010), increasing the diversity of this pathogen. The fungus can spread either via spores by wind or rain (Guerin et al. 2001) or via infected plant material relocated by humans (Anagnostakis 1987). All of this ranks $C$. parasitica highly in risk assessment strategies (McDonald and Linde 2002).

C. parasitica is a pathogen to which the sweet chestnut is not resistant. Rather than applying the strict gene-for-gene model usually 
used in describing resistance and susceptibility of plants to pathogens, the sweet chestnut shows a variation of tolerance to infection with C. parasitica between different tree genotypes (Ježić et al. 2014; Krstin et al. 2016). Because the sweet chestnut is a perennial plant, the established populations tend to be genetically stable over decades or even centuries. This means that the potential spread of tolerant genotypes is slow and gradual.

The Cryphonectria hypovirus 1 (CHV1) infects C. parasitica and can reduce both virulence (Van Alfen et al. 1975) and female fertility of the fungus (Peever et al. 2000; Zhang et al. 1998). This can halt the progression of the disease considerably by transforming aggressive, actively growing lesions (cankers) into inactive ones, allowing the affected tree to form a callus and close the wound (Grente 1965). Such trees may survive the initial disease outbreak, allowing tolerant sweet chestnut genotypes to endure long enough to reproduce and increase in frequency.

Vegetative incompatibility (vic) loci of $C$. parasitica, which regulate the stability of anastomoses between genetically different hyphae, are under weak selection pressure, at least in Europe and the United States (Milgroom and Cortesi 1999). However, in populations in which CHV1 is present, the spread of which occurs via hyphal anastomoses and is dependent on vegetative compatibility of the affected mycelia, the virus might impose selection pressure against certain $C$. parasitica genotypes rather than on particular vic loci. Therefore, the allelic richness of these loci might not be as expected (i.e., low or high genetic diversity might not necessarily imply a younger or older population, respectively) (Barrett et al. 2008). These populations must be monitored so that a trend in genetic diversity change can be established and justifiable conclusions about the populations made, in order to make the best predictions and modify human-mediated biological control of the disease accordingly. It was noted that the application of fungicides may alter the genetic structure of fungal pathogens (McDonald and Linde 2002), and CHV1 may also influence the genetic structure of $C$. parasitica populations.

In order to better understand the processes involved in natural progression of the disease, we have investigated temporal changes in two $C$. parasitica populations growing in different regions of Croatia: Buje, with a sub-Mediterranean climate, and Hrvatska Kostajnica, with a continental climate. We have sampled the populations over the course of 3 years (from 2014 to 2016) and compared the results with those collected in 2004 by Krstin et al. (2008). It was shown that, in 2004, these two populations exhibited similar population diversity but different percentage of CHV1 hypovirulence: $12.7 \%$ in the Buje population and $50.8 \%$ in the Hrvatska Kostajnica population (Krstin et al. 2008). The aims of our study were to (i) estimate the long-term (over the course of 10 years) changes in population structure of $C$. parasitica, (ii) determine the impact of high and low hypovirulence incidence on the disease progression, and (iii) reveal the short-term disease dynamic over the course of 3 years by assessing changes in disease presentation, population structure, and hypovirulence incidence in cankers.

\section{MATERIALS AND METHODS}

Sampling and canker assessment. In early summer 2014, samples from 63 cankers in Buje and 77 cankers in Hrvatska Kostajnica on randomly chosen chestnut trees were collected. Only one canker per tree was sampled and trees were at least $10 \mathrm{~m}$ apart from each other. The same 63 cankers were sampled again in 2015 and 2016 in Buje. One of the selected trees in Hrvatska Kostajnica was removed in 2015; therefore, only 76 cankers were sampled in 2015 and 2016 from that population. The length and width of every canker, as well as circumference of the tree measured at the breast height, were recorded during every sampling. Cankers were visually inspected for the presence of perithecia and characterized as: active and aggressive, expanding on the chestnut bark and in the cambium, with a visible deep wound; callus, healing of the canker by the formation of callusing tissue around the wound which partially or completely enclosed the wound; necrosis, slowly growing, superficial canker of the bark; or active and callus, if callus tissue only partially covered the bark wound. Because the canker assessment can be somewhat subjective, it was always performed by the same person to decrease the inconsistencies between samplings. Each canker was sampled three times with an approximately 2-mm bonemarrow biopsy needle, producing three bark plugs per canker: one near the upper margin, one in the center, and one near the lower margin of the canker. Between each sampling, the needle was dipped in $96 \%$ ethanol and flamed for a few seconds. The samples were processed the next day in the laboratory.

Sample cultivation. The bark plugs were surface sterilized by dipping them in $70 \%$ ethanol for several seconds, then dried on sterile filter paper. Three bark plugs obtained from the same canker were then placed in approximately $90-\mathrm{mm}$ Petri dishes containing approximately $20 \mathrm{ml}$ of potato dextrose agar (PDA) (Difco, BD, Franklin Lakes, NJ), and placed in a growth chamber at $24^{\circ} \mathrm{C}$ and $70 \%$ humidity in the dark. After several days, hyphal tips from the freshly grown mycelia expanding from bark samples were transferred to new Petri dishes with fresh PDA. To obtain as many isolates as possible, contaminated samples were then transferred to PDA supplemented with ampicillin (Roth, Karlsruhe, Germany) at $200 \mathrm{mg} \mathrm{liter}^{-1}$ and rifampicin (Roth) at $10 \mathrm{mg} \mathrm{liter}^{-1}$ and grown for several days; then, hyphal tips were subcultured on fresh PDA.

Nucleic acid extraction. DNA was extracted from all isolates and utilized for molecular vegetative compatibility genotyping, while RNA was extracted only from isolates for which colony morphology could not be unambiguously determined (i.e., whether the isolate was virulent or hypovirulent).

For nucleic acid extraction, a small cube of PDA containing newly grown mycelia was transferred to a Petri dish with cellophane over the PDA, and grown for 5 days in the conditions mentioned above. The mycelia were scraped and fungal DNA was isolated using the commercially available DNA extraction kit OmniPrep for Fungi (G Biosciences, St. Louis, MO), while viral RNA was extracted with the Double-RNA Viral dsRNA Extraction Mini Kit (For Plant Tissue) (iNtRON Biotechnology, Seoul, Korea). Both procedures were performed according to the manufacturers' recommendations. The extracted DNA and RNA were immediately processed and utilized for molecular characterization of vic genotypes and hypovirulence assessment.

Vegetative compatibility genotyping and hypovirulence assessment. Molecular vegetative compatibility genotyping was performed with primer sets constructed by Short et al. (2015) and Mlinarec et al. (2017). The polymerase chain reaction (PCR) conditions as well as electrophoresis for amplicon visualization were as described by Mlinarec et al. (2017). The genotypic profile of each isolate was assigned to a vegetative compatibility (vc) type as proposed by Cortesi and Milgroom (1998). Following that, traditional coculturing of the $C$. parasitica isolates with 64 tester strains was utilized to confirm the assigned vc types and to easily assess the morphology of the collected $C$. parasitica isolates (Cortesi et al. 1998). All isolates collected for this study were characterized in that manner. Whereas hypovirulent isolates of the same vc type as the tester strain would be able to transmit CHV1 easily, changing the tester strain's morphology from orange to white, the virulent isolates would not affect the morphology of the tester strains. Isolates which clearly converted tester strains' morphology from orange to white were considered hypovirulent, while isolates which had deep orange color and did not convert tester strains were considered virulent. If the isolate's morphology was ambiguous (i.e., we could not determine whether it was virulent [orange morphology] or hypovirulent [white morphology]), RNA was extracted as described above. Agarose gel electrophoresis was performed in $0.7 \%$ (wt/vol) agarose gel (Sigma-Aldrich, St. Louis) and $0.5 \times$ Tris-borate-EDTA (TBE) (Lonza, Basel, Switzerland) at 
$5 \mathrm{~V} / \mathrm{cm}$ for 90 min using $10 \mu \mathrm{l}$ of the RNA extract. The gels were prestained with GelStar (Lonza) and the nucleic acids were visualized with DigiGenius gel dock (Syngene, Cambridge, UK). If the approximately 12.7-kb CHV1 genomic double-stranded (ds) RNA was not visible, cDNA synthesis was performed with GoScript Reverse Transcription System (Promega Corp., Madison, WI). Amplification of open reading frame ORF-A and ORF-B segments was performed in $25-\mu \mathrm{l}$ reactions with primer pairs and cycling conditions as described by Allemann et al. (1999). The PCR products were then subjected to electrophoresis in $1 \%(\mathrm{wt} / \mathrm{vol})$ agarose gel and $0.5 \times \mathrm{TBE}$ at $7 \mathrm{~V} / \mathrm{cm}$ for $60 \mathrm{~min}$. The gels were also prestained with GelStar and the nucleic acids were visualized. Appropriate positive (RNA extract from hypovirulent $C$. parasitica strain), negative (RNA extract from virulent $C$. parasitica strain), and water controls were utilized.

Data analysis. The data from the previous sampling (Krstin et al. 2008) were available and used together with the new data from the years 2014, 2015, and 2016. Krstin et al. (2008) used a coculturing assay for vc type determination, while hypovirulence assessment was done the same way as described here. For each isolate from each location and sampling year, vc type and colony morphology (CHV1 presence or absence) were recorded. The Shannon index

$$
\left(H^{\prime}=-\sum_{i} \frac{n_{i}}{n} \ln \frac{n_{i}}{n}\right)
$$

and equitability $\left(e=H^{\prime} / \ln N\right)$ of the analyzed populations were calculated using Past (Paleontological Statistics, version 3.14) (Hammer et al. 2001). In order to estimate whether a significant change in general population structure has occurred in the last 10 years, the Kolmogorov-Smirnov and Mann-Whitney $U$ tests were performed on the vc type frequency datasets for both populations from the sampling from 10 years ago (Krstin et al. 2008) and from the 2014 sampling. Next, to assess the change in hypovirulence prevalence among different vc types, isolates obtained from the same location and year were subdivided according to their colony morphology (orange $=$ virulent and $\mathrm{CHV} 1$ free and white = hypovirulent and CHV1 infected), and vc type frequency among virulent and hypovirulent isolates was recalculated. The Kolmogorov-Smirnov and Mann-Whitney $U$ tests were performed on the frequencies of vc types of virulent and hypovirulent subsets of isolates for each population from every sampling year: on the sample from a decade ago as well as for the samplings obtained in this study. All $P$ values were obtained after the Monte Carlo permutation test as implemented in Past (Hammer et al. 2001).

Short-term changes in disease presentation were analyzed on a single canker level. To determine whether canker size correlates with the morphology of $C$. parasitica isolate obtained from the canker, canker length was divided by the circumference of the tree to control for the tree size, as described by Bryner et al. (2013). This was done only for the data obtained in 2014, because the successive samplings were not random but deliberate resampling from the same cankers. The cankers were approximated as ellipses, the area of which was calculated as $A=a b \pi / 4$, where $a$ and $b$ were major (length) and minor (width) axes of the cankers, respectively. The descriptive statistics (hypovirulence incidence in the population, canker size growth over the seasons 2014-15 and 2015-16, rate of successful isolation of $C$. parasitica from cankers, number of cankers from which more than one fungal isolate was obtained, number of cankers with vc type discordant isolates, and number of cankers with morphologically discordant isolates) were calculated in Microsoft Excel.

\section{RESULTS}

Changes in genetic structure of $\boldsymbol{C}$. parasitica populations. Genetic diversity of $C$. parasitica increased for both populations from 2004 to 2014 . The Shannon diversity index for both populations increased significantly as well, from $1.69(95 \%$, confidence interval [CI] 1.41 to 1.85$)$ to $2.56(95 \%$, CI 2.33 to 2.68$)$ in Buje and from $1.58(95 \%$, CI 1.32 to 1.75$)$ to $2.49(95 \%$, CI 2.15 to 2.62$)$ in Hrvatska Kostajnica (Table 1). Genetic diversity slowly continued to grow from 2014 to 2016 in both populations. Although the number of different vc types increased from 8 in both populations in 2004 to 20 in Buje and 21 in Hrvatska Kostajnica in 2014, only a slight, statistically insignificant increase in equitability was observed-from 0.81 (95\%, CI 0.70 to 0.89$)$ to 0.85 (95\%, CI 0.80 to 0.90$)$ in Buje and from $0.76(95 \%$, CI 0.67 to 0.86$)$ to $0.82(95 \%$, CI 0.75 to 0.88 ) in Hrvatska Kostajnica-indicating that the equality of abundance of different vc types did not change over the years (Table 1). A traditional coculturing assay confirmed the validity of the molecular vc typing, because no barrage and colony merger between the $C$. parasitica isolates and vc tester of the same European (EU) type was observed.

In 2004, the dominant vc types in Buje were EU-1 and EU-17 whereas, in Hrvatska Kostajnica, the most common vc types were EU-1, EU-2, and EU-12. In 2014, EU-1 remained one of the most abundant vc types in both populations, while EU-4, EU-5, and EU-13 became quite widespread in Buje and EU-5 in Hrvatska Kostajnica. On the other hand, the abundance of EU-17 isolates in Buje decreased drastically (Fig. 1). Several new, previously unobserved vc types were recorded: EU-3, EU-12, EU-20, and EU44 in Buje; EU-9, EU-13, EU-16, EU-17, EU-18, EU-23, EU-25, EU27, and EU-28 in Hrvatska Kostajnica; and EU-6, EU-7, EU-8, EU-14, EU-15, EU-19, EU-21, EU-22, EU-24, EU-26, EU-30, and EU-31 in both populations. Over the 3 years of our observation, the abundances of vc types varied only slightly.

The Buje and Hrvatska Kostajnica populations changed significantly from 2004 to 2014 in both the distribution of vc types and the median of vc type frequency. Surprisingly, the Buje and Hrvatska Kostajnica populations from 2004, as well as the populations from 2014, did not differ from each other (Table 2).

Hypovirulence incidence changes in $C$. parasitica populations. Most of the isolates for which colony morphology was ambiguous were hypovirulent (i.e., CHV1 12.7-kb genomic dsRNA was detected either directly after electrophoresis on agarose gels or

TABLE 1. Population diversity indices for Cryphonectria parasitica populations in Buje and Hrvatska Kostajnica

\begin{tabular}{|c|c|c|c|c|c|c|c|c|c|c|}
\hline \multirow[b]{2}{*}{ Sampling year } & \multicolumn{5}{|c|}{ Buje } & \multicolumn{5}{|c|}{ Hrvatska Kostajnica } \\
\hline & $N^{\mathrm{a}}$ & $\mathrm{vc}^{\mathrm{b}}$ & Hypo $(\%)^{\mathrm{c}}$ & $H^{\prime} \mathrm{d}$ & $e^{\mathrm{e}}$ & $N^{\mathrm{a}}$ & $\mathrm{vc}^{\mathrm{b}}$ & Hypo $(\%)^{\mathrm{c}}$ & $H^{\prime \mathrm{d}}$ & $e^{\mathrm{e}}$ \\
\hline 2004 & 47 & 8 & 12.7 & 1.69 & 0.81 & 50 & 8 & 50.8 & 1.58 & 0.76 \\
\hline 2014 & 82 & 20 & 19.5 & 2.56 & 0.86 & 77 & 21 & 29.9 & 2.49 & 0.82 \\
\hline 2015 & 79 & 19 & 22.8 & 2.65 & 0.90 & 79 & 17 & 55.7 & 2.50 & 0.88 \\
\hline 2016 & 94 & 21 & 57.5 & 2.73 & 0.90 & 117 & 24 & 72.7 & 2.62 & 0.82 \\
\hline
\end{tabular}

a Number of samples.

b Number of vegetative compatibility (vc) types.

c Hypovirulent isolates.

d Shannon index.

e Equitability. 
after reverse-transcription [RT]-PCR). Regarding our controls, the isolates that were determined as virulent in the coculture assay never produced appropriate amplicons after the RT-PCR, whereas the hypovirulent ones consistently did. The incidence of hypovirulence changed over the period of 10 years in both populations. The prevalence of hypovirulent isolates increased slightly in Buje from 12.7 in 2004 to $19.5 \%$ in 2014 whereas, in the same time span in Hrvatska Kostajnica, it decreased substantially from 50.8 to $29.9 \%$ (Table 1 ).

The prevalence of hypovirulent isolates collected from the same canker over the years 2014 to 2016 increased steadily, rising from 19.5 to $57.4 \%$ in Buje and from 29.9 to $72.6 \%$ in Hrvatska Kostajnica (Table 1). Although, 10 years ago, the general population structure of both populations was similar (Table 2), the distribution of different vc types among virulent and hypovirulent isolates was not. The Kolmogorov-Smirnov test showed that, in 2014, the distribution of vc types was statistically different $(P$ value $=0.0438)$ between virulent and hypovirulent subsets of isolates from Buje, while the Mann-Whitney $U$ test $(P$ value $=0.0142)$ revealed that there was a difference in vc type frequencies median between the same subsets of isolates. In Hrvatska Kostajnica, such differences were not observed in either the distribution of vc types $(P$ value $=$ $0.7703)$ or the median of vc type frequencies $(P$ value $=0.5722)$ (Table 3).

In the Buje population, a significant difference in the distribution of $\mathrm{vc}$ type frequencies and in the median of vc type frequencies between hypovirulent and virulent isolates persisted in 2014. This continued in 2015 but was not observed in 2016. The opposite trend was observed in Hrvatska Kostajnica: virulent and hypovirulent isolates had a similar distribution of vc type frequencies and median of vc type frequencies in 2014 and 2015 but, by 2016, that was no longer the case (Table 3 ).
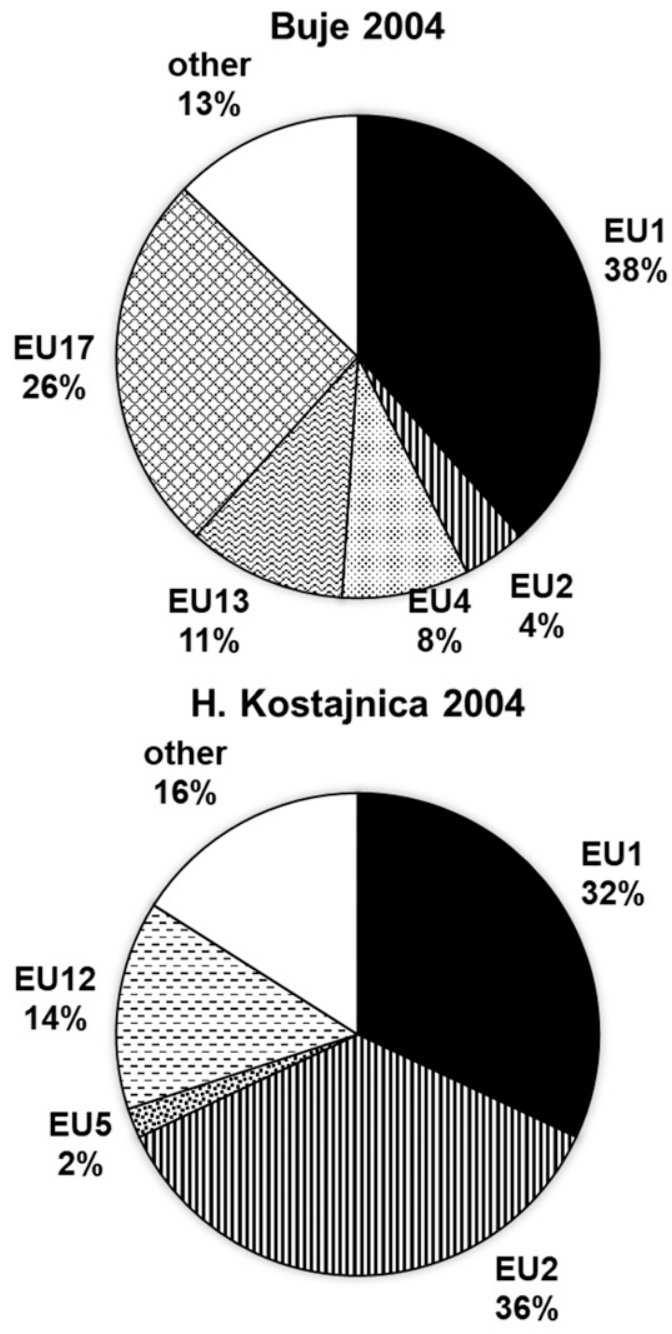

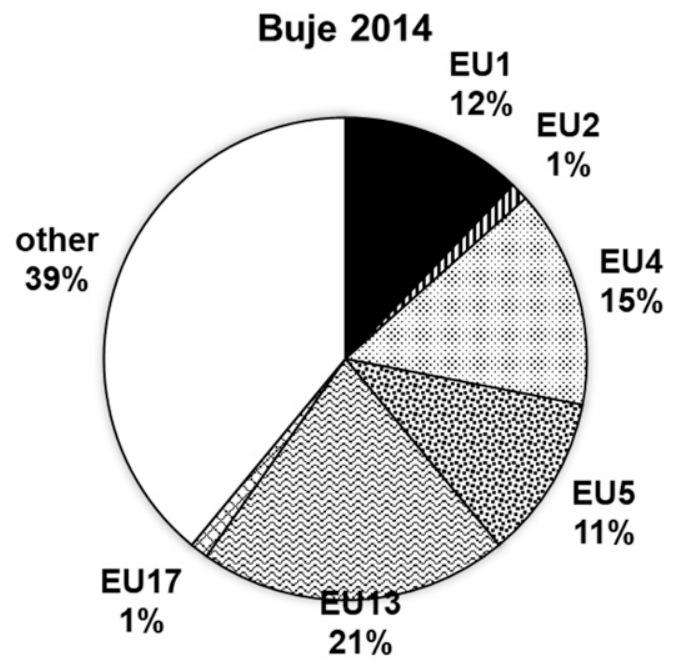

H. Kostajnica 2014

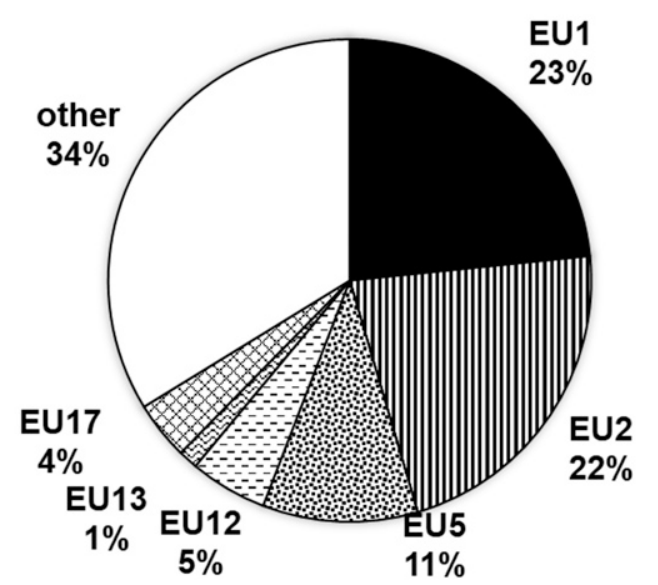

Fig. 1. Change in abundance of dominant vegetative compatibility types in populations Buje and Hrvatska Kostajnica between 2004 and 2014.

TABLE 2. Kolmogorov Smirnov and Mann-Whitney $U$ test of significant differences between distribution and frequency median of vegetative compatibility types of populations Buje and Hrvatska Kostajnica sampled in 2004 and $2014^{\mathrm{a}}$

\begin{tabular}{lcc}
\hline Population pair compared & Kolmogorov Smirnov & Mann-Whitney U \\
\hline Buje 2004 and Hrvatska Kostajnica 2004 & 0.954 & 0.8939 \\
Buje 2004 and 2014 & $0.0003^{*}$ & $0.0062^{*}$ \\
Hrvatska Kostajnica 2004 and 2014 & $0.0006^{*}$ & $0.0105^{*}$ \\
Hrvatska Kostajnica 2014 and Buje 2014 & 0.1969 & 0.5694 \\
\hline
\end{tabular}

\footnotetext{
a Significant $P$ values $(<0.05)$ are indicated with asterisk.
} 
Changes in canker size and morphology. There was no statistical difference between the ratio of canker length and girth of the tree between cankers harboring virulent, hypovirulent, or both types of $C$. parasitica isolates. The ratio ranged from 0.72 for hypovirulent cankers in Hrvatska Kostajnica to 1.23 for cankers with both virulent and hypovirulent isolates in Buje. Cankers sampled from Hrvatska Kostajnica were somewhat smaller but also not statistically significant.

Most of the cankers increased in size over the 2014 to 2016 period but the growing rates were different in Buje and Hrvatska Kostajnica (Table 4). In Buje, most of the cankers increased in size by 25 to $50 \%$ every year while, in Hrvatska Kostajnica, approximately $50 \%$ of cankers increased in size by 5 to $25 \%$ over a single season. In Hrvatska Kostajnica, a slight increase in the growth rate of the cankers over the years was noticed. Visual inspection of the cankers in the field consistently revealed the presence of fruiting bodies (Table 4).

It was not possible to efficiently visually distinguish active cankers harboring virulent isolates from the cankers with hypovirulent $C$. parasitica isolates (data not shown). Cankers which were described as active usually showed slightly higher growth rates than cankers described as calluses or necroses (inactive cankers) but the differences were not significant (Fig. 2).

The most interesting observation was the change in callusing cankers; in Buje, we started monitoring seven completely healed calluses in 2014 but, by 2016, six of them had been reinvaded by virulent $C$. parasitica. In Hrvatska Kostajnica, seven of nine calluses were reinvaded by virulent $C$. parasitica; however, five of them only transiently. The cankers categorized as active and callus over the years appeared to either progress toward complete healing or were reinvaded by virulent $C$. parasitica isolates, reactivating and increasing the growth rate.

Changes of $C$. parasitica isolates' morphology and ve type within individual cankers over 3 years (2014 to 2016). C. parasitica was successfully isolated from at least two-thirds of the sampled cankers. The isolation rate was somewhat higher in 2016, especially from samples obtained in Hrvatska Kostajnica (Table 5). Among cankers from which multiple isolates were successfully obtained, between 20.8 and $47.8 \%$ of them contained both virulent and hypovirulent $C$. parasitica isolates. In the 3 years of the study, the proportion of cankers harboring hypovirulent isolates increased from 28.8 to $66.7 \%$ in Buje and from 37.0 to $78.4 \%$ in Hrvatska Kostajnica. Furthermore, in Buje, between 21.7 and $45.8 \%$ of cankers from which multiple isolates were obtained harbored two or more vc types whereas, in Hrvatska Kostajnica in 2016 , almost $70 \%$ of cankers contained at least two isolates of different vc type. Isolates belonging to different vc types were obtained occasionally from the same canker over the years. In extreme case, between 2014 and 2015 in Hrvatska Kostajnica, isolates of different vc types were found from as many as $50 \%$ of the sampled cankers (Table 5).

\section{DISCUSSION}

Temporal population structure changes of fungal pathogens in trees have been studied only occasionally (Brasier et al. 2004). The majority of temporal-scale research, although also scarce, has been done on annual crops and their fungal pathogens. For example, Naegele et al. (2016) found that changes in the population structure and genetic diversity of Pseudoperonospora cubensis infecting cucumber occurred within a month, probably because of an influx of new individuals. Conversely, in populations of Sclerotinia sclerotiorum infecting potato, no statistically significant differences in the genetic structure between different years of sampling were observed (Atallah et al. 2004). Considering longer time periods, in wheat pathogen Puccinia striiformis, the differentiation between some of the old and new populations suggests that the old strains were being replaced by new, migrating, and highly virulent genotypes (Thach et al. 2016). This study was to accommodate both aspects of pathogen population structure change: (i) long term, over the course of 10 years, which was achieved by revisiting exactly the same populations that were analyzed in previous research by (Krstin et al. 2008); and (ii) short term, by monitoring the same cankers every year over the course of our experiment.

Our research provided evidence that the population structure of pathogenic fungus $C$. parasitica infecting a tree species can radically change in a decade. The population diversity in both populations increased significantly within 10 years, indicated by the doubling of the number of vc types and the increase in Shannon's diversity index. Although the populations studied in this article have descended from the populations studied by Krstin et al. (2008), quite a substantial population differentiation has occurred since then, related to the appearance of new vc types. Although EU-1, one of the most common vc types in Europe and in neighboring countries such as Slovenia (Krstin et al. 2011), northwestern Bosnia (Trestić et al. 2001), and Italy (Cortesi et al. 1996), is still present in a high proportion in both investigated populations, other vc types have appeared and increased in number. Because equitability remained more or less unchanged, we can conclude that, although new vc types appeared in the studied populations, none of them managed to dominate the others or completely replace the old ones. The observed changes can be explained by either a continuous influx of new vc types from other populations, sexual reproduction

TABLE 4. Increase of the canker size in Buje and Hrvatska Kostajnica from 2014 to 2016 . The cankers were divided into four growth categories: minimal growth ( 0 to $5 \%$ increase in canker area), slight growth (5 to $25 \%$ increase of canker area), significant growth (25 to $50 \%$ increase of canker area), and extreme growth (over $50 \%$ increase of canker area)

\begin{tabular}{|c|c|c|c|c|c|c|c|c|}
\hline \multirow[b]{3}{*}{$\%$ increase $^{\mathrm{b}}$} & \multicolumn{4}{|c|}{ Buje } & \multicolumn{4}{|c|}{ Hrvatska Kostajnica } \\
\hline & \multicolumn{2}{|c|}{$2014-15^{\mathrm{a}}$} & \multicolumn{2}{|c|}{$2015-16^{\mathrm{a}}$} & \multicolumn{2}{|c|}{$2014-15^{\mathrm{a}}$} & \multicolumn{2}{|c|}{$2015-16^{\mathrm{a}}$} \\
\hline & $N^{\mathrm{c}}$ & $\%^{\mathrm{d}}$ & $N^{\mathrm{c}}$ & $\%^{\mathrm{d}}$ & $N^{\mathrm{c}}$ & $\%^{\mathrm{d}}$ & $N^{\mathrm{c}}$ & $\%^{\mathrm{d}}$ \\
\hline 0 to $5 \%$ & 7 & 11.11 & 7 & 11.11 & 20 & 26.32 & 16 & 21.05 \\
\hline 5 to $25 \%$ & 17 & 26.98 & 28 & 44.44 & 40 & 52.63 & 38 & 50.00 \\
\hline 25 to $50 \%$ & 20 & 31.75 & 23 & 36.51 & 13 & 17.11 & 18 & 23.68 \\
\hline$>50 \%$ & 19 & 30.16 & 5 & 7.94 & 3 & 3.95 & 4 & 5.26 \\
\hline
\end{tabular}

a Season for which the growth of cankers was measured.

b Percent increase in canker area.

c Number of cankers in particular growth category.

d Percentage of cankers in particular growth category.

TABLE 3. Kolmogorov-Smirnov and Mann-Whitney $U$ tests of significant differences in distribution and frequencies median between virulent and hypovirulent isolates belonging to different vegetative compatibility types in populations Buje and Hrvatska Kostajnica ${ }^{a}$

\begin{tabular}{|c|c|c|c|c|}
\hline \multirow[b]{2}{*}{ Sampling year } & \multicolumn{2}{|c|}{ Buje } & \multicolumn{2}{|c|}{ Hrvatska Kostajnica } \\
\hline & Kolmogorov Smirnov & Mann-Whitney U & Kolmogorov Smirnov & Mann-Whitney U \\
\hline 2004 & $0.0438 *$ & $0.0142 *$ & 0.7703 & 0.5722 \\
\hline 2014 & $0.0403 *$ & $0.0032 *$ & 0.1195 & 0.1128 \\
\hline 2015 & $0.0014 *$ & $0.0011 *$ & 0.8108 & 0.7519 \\
\hline 2016 & 0.4304 & 0.3248 & $0.0368 *$ & $0.0146 *$ \\
\hline
\end{tabular}

a Significant $P$ values $(<0.05)$ are indicated with asterisk. 
of the resident isolates belonging to different vc types which creates recombinants in the process, or a combination of these two processes (Ježić et al. 2012). Similar results, albeit over a longer time period (1992 to 2012), were observed in Germany (Peters et al. 2014). The authors demonstrated the increase in the diversity of the vc types of German $C$. parasitica populations, and argue that the chestnut forests of southwestern Germany experienced several introduction events from two different sources, resulting in the contemporary populations. The authors argue that sexual reproduction appears to be rare but both mating types, revealed by the presence of both MAT idiomorphs, were detected, suggesting an opportunity for sexual events in the near future. A similar increase in the number of vc types was observed in the United States at epidemic sites, where the MAT idiomorph ratio was 50:50 and hypovirulence incidence low (Springer et al. 2013). Between 1996 and 2009, they observed a surge in number of vc types from 12 to 29 , implicating sexual reproduction as the main cause. In Croatia, both MAT idiomorphs have been found in C. parasitica populations (Krstin et al. 2008), as well as perithecia on the studied cankers in this study, suggesting similar processes occurring in our studied populations.
Our effort to efficiently and accurately determine the vc type of $C$. parasitica isolates utilizing molecular typing and then confirm the assessment via a coculturing assay seems to confirm the results of Mlinarec et al. (2017), in which the suitability of the method was evaluated. Regarding the morphology of the investigated isolates (i.e., whether they are infected with CHV1), the coculturing assay and colony morphology seems to be a good predictor of hypovirulence status in most cases. Isolates with intermediate morphology, however, should always be assayed via RT-PCR to ensure the correct assessment of the hypovirulence status.

The results of this study showed a slight increase in the incidence of hypovirulence from $12.7 \%$ in 2004 (Krstin et al. 2008) to $19.5 \%$ in 2014 in Buje, and a decrease from 50.8\% in 2004 (Krstin et al. 2008) to $29.9 \%$ in 2014 in Hrvatska Kostajnica. Therefore, despite the changes in population structure, it seems that the incidence of hypovirulence has leveled out. The distribution of hypovirulent and virulent isolates among different vc types was statistically different in the Buje population in 2004 but not in the Hrvatska Kostajnica population, signifying that hypovirulent isolates are more evenly distributed among residential $C$. parasitica vc types in the latter

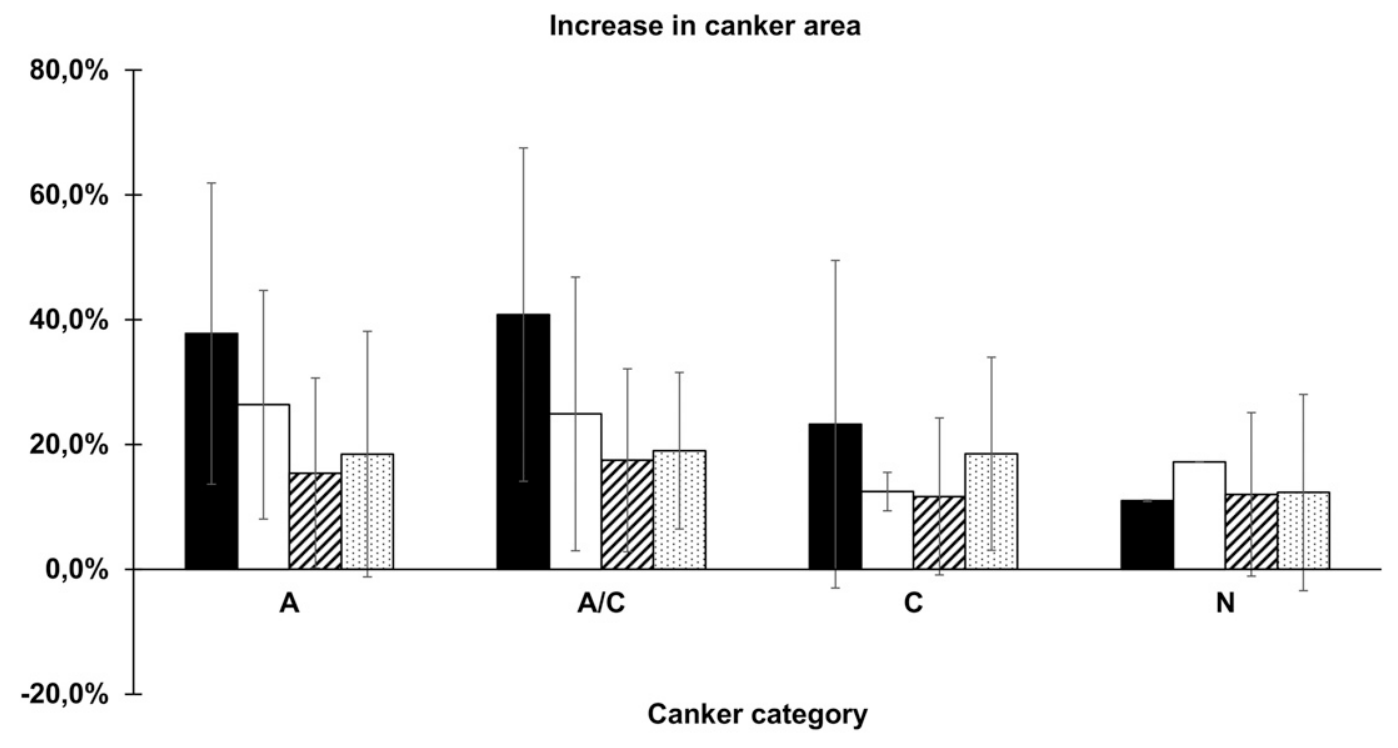

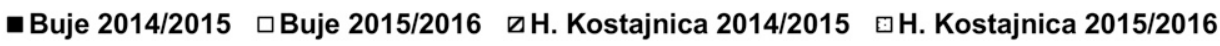

Fig. 2. Increase of the canker size (in percentage) of differently categorized cankers in Buje and Hrvatska Kostajnica. Standard deviations are given with error bars. Canker categories are (A) active and aggressive, $(\mathrm{A} / \mathrm{C})$ active and callus, $(\mathrm{C})$ callus, and $(\mathrm{N})$ necrosis.

TABLE 5. Canker characteristics with respect to the vegetative compatibility (vc) type and morphology of Cryphonectria parasitica from populations Buje and Hrvatska Kostajnica over 3 years (2014 to 2016)

\begin{tabular}{|c|c|c|c|c|c|c|}
\hline & \multicolumn{3}{|c|}{ Buje } & \multicolumn{3}{|c|}{ Hrvatska Kostajnica } \\
\hline & 2014 & 2015 & 2016 & 2014 & 2015 & 2016 \\
\hline Total number of cankers sampled & 63 & 63 & 63 & 77 & 76 & 76 \\
\hline Successful isolation of $C$. parasitica ${ }^{\mathrm{b}}$ & $52(82.5)$ & $51(81.0)$ & $54(85.7)$ & $54(70.1)$ & $50(65.8)$ & $74(97.4)$ \\
\hline Cankers which changed vc type ${ }^{d}$ & N/A & $21(41.2)$ & $19(35.2)$ & N/A & $25(50.0)$ & $35(47.3)$ \\
\hline \multicolumn{7}{|l|}{ Cankers with } \\
\hline At least two isolates $\mathrm{e}^{\mathrm{e}}$ & $23(36.5)$ & $24(38.1)$ & $28(44.4)$ & $17(22.1)$ & $23(30.3)$ & $19(38.2)$ \\
\hline
\end{tabular}

a Years indicate sampling year and data in parentheses represent percentage of cankers belonging to particular category; N/A = not applicable.

b Cankers from which $C$. parasitica was successfully isolated out of total number of cankers sampled.

${ }^{c}$ Cankers from which at least one hypovirulent $C$. parasitica isolate was obtained after successful isolation.

${ }^{\mathrm{d}}$ Cankers which harbored different vc type between years of sampling after successful isolation.

e Cankers with at least two isolates obtained out of total number of cankers sampled.

${ }^{\mathrm{f}}$ Cankers with more than one vc type present out of cankers from which at least two isolates were obtained.

$\mathrm{g}$ Cankers with both virulent and hypovirulent isolates were present out of cankers from which at least two isolates were obtained. 
population. This indicates that the naturally established hypovirulence in that population is superior in biological control of the disease. The situation remained the same in 2014 for both populations - similar distribution of vc type frequencies for both virulent and hypovirulent isolates but an excess of virulent isolates in Buje, indicating that, in this population, a disproportion between the frequencies of virulent and hypovirulent isolates persists. Possible explanations of this phenomenon are that the newly arrived isolates had a very low incidence of hypovirulence, or that derived (recombinant and virulent) vc types quickly established themselves in the population. In Hrvatska Kostajnica, a decrease in hypovirulence prevalence accompanied by an increase in vc type diversity is very similar to the situation observed by Springer et al. (2013). The authors suggest that, depending on whether or not the conditions are favorable, mycoviruses are either going to spread within a population or be lost from it.

During the course of 3 years, as we revisited the same trees and cankers and attempted reisolation of $C$. parasitica from the same lesions, we observed a steady increase in the incidence of hypovirulence. This means that the samples from 2015 and 2016 were not obtained randomly, like the 2014 samples; rather, we intentionally collected bark samples from the same cankers to observe the changes of the specific canker. Over the 3 years, most of the cankers harbored hypovirulent isolates, suggesting a highly dynamic system that responds to $\mathrm{CHV} 1$ pressure in the population. The number of cankers harboring hypovirulent isolates increased in both studied populations. This indicated that, even in populations with a relatively low proportion of hypovirulent isolates, the CHV1 transmission into virulent isolates occurs regularly, efficiently transforming them. A similar increase of isolates infected with mycoviruses was also reported for populations of Heterobasidion parviporum (Vainio et al. 2015). In the population of Buje, which had a low prevalence of hypovirulence and unbalanced distribution of hypovirulent isolates among different vc types, the proportion of hypovirulent isolates substantially increased in the monitored cankers between 2014 and 2016, changing the population structure in the process. In the population of Hrvatska Kostajnica, the distribution of virulent and hypovirulent isolates among different vc types became unbalanced in 2016. There are several hypotheses which might explain this observation: random population structure shift, a short-term occurrence, or an artifact of the sampling method. Alternatively, the excess of hypovirulent isolates obtained in 2016 might have influenced the statistics. For example, Double et al. (2013) observed an increase in the number of hypovirulent isolates obtained from older cankers, as well as numerous other fungi that constitute the biota of cankers. We did notice the increase in the number of hypovirulent isolates as well but percentage of cankers from which $C$. parasitica was successfully isolated remained high thought the years, indicating that, during our experiment, the monitored cankers did not get excessively colonized by other microorganisms. The overall higher successful isolation rate of C. parasitica from Buje and, in 2016, from Hrvatska Kostajnica is probably due to favorable weather conditions, with less moisture during sampling.

The morphology of the isolates could not be satisfactorily correlated with the size of the canker, an observation similar to the one from Bryner et al. (2013). The results of this study undoubtedly showed that the canker area increased over the 3 years of investigation, even in cankers harboring hypovirulent isolates. As the disease spreads, new aggressive cankers are initiated but only a small part of them is converted to healing (callusing) ones. This result was unexpected because the number of hypovirulent isolates obtained over the years from the same cankers in both populations increased. We noticed a slight decrease in canker growth rate in Buje, as well as a slight increase in Hrvatska Kostajnica, but nothing statistically significant, probably indicating a normal variation of the disease severity over the years. Several cankers, categorized as active and callus, progressed over the years toward either almost complete healing or reopening and reactivating, due to the invasion of the wound by virulent $C$. parasitica isolates. A trend could be established only by monitoring the cankers over the years because, in 2014, we were unable to distinguish between healing and reopening cankers. We also noticed cankers that harbored both virulent and hypovirulent isolates, or isolates that belonged to different vc types. This was previously observed in $C$. parasitica epidemiology where, in a single canker, several vc types as well as isolates discordant in colony morphology can occur (Hogan and Griffin 2002). Similar observations were made for Mycosphaerella graminicola where, within one lesion, up to six different genotypes can be present at the same time (Linde et al. 2002). All of this indicates that lesions caused by phytopathogenic fungi are a highly dynamic system in which, over a relatively short period of time, quite significant shifts in type composition and, in the case of $C$. parasitica, hypovirulence incidence can occur. The system responds and adapts to the presence of CHV1 by slowly shifting toward the equilibrium, spreading the virus to the uninfected isolates in a population and, through it, halting the progress of the disease. On the other hand, the $C$. parasitica population, given the opportunity, responds to the increasing number of hypovirulent isolates by reproducing sexually, developing novel vc genotypes. These recombinant vc genotypes might be able to resist the CHV1 infection, at least temporarily.

Sweet chestnut-C. parasitica-CHV1 is a highly dynamic system in which small shifts in population structure and hypovirulence incidence can happen even within a few years. On the other hand, a longer period, such as a decade, may completely change the genetic composition of the $C$. parasitica population. However, even in such dramatic shifts, hypovirulent isolates belonging to different $\mathrm{vc}$ genotypes can be maintained. Studies of temporal changes of plant pathogens are clearly necessary to predict the future state of the affected landscapes and to ascertain the proper phytosanitary measures.

\section{LITERATURE CITED}

Allemann, C., Hoegger, P., Heiniger, U., and Rigling, D. 1999. Genetic variation of Cryphonectria hypoviruses (CHV1) in Europe, assessed using restriction fragment length polymorphism (RFLP) markers. Mol. Ecol. 8: 843-854.

Anagnostakis, S. 1987. Chestnut blight: The classical problem of an introduced pathogen. Mycologia 79:23-37.

Atallah, Z. K., Larget, B., Chen, X., and Johnson, D. A. 2004. High genetic diversity, phenotypic uniformity, and evidence of outcrossing in Sclerotinia Sclerotiorum in the Columbia Basin of Washington State. Phytopathology 94:737-742.

Barrett, S. C. H., Colautti, R. I., and Eckert, C. G. 2008. Plant reproductive systems and evolution during biological invasion. Mol. Ecol. 17:373-383.

Biraghi, A. 1946. Il cancro del castagno causato da Endothia parasitica. Ital. Agric. 7:1-9.

Brasier, C., Kirk, S., Buck, K., Paoletti, M., and Crawford, L. 2004. Molecular analysis of evolutionary changes in populations of Ophiostoma novo-ulmi. For. Syst. 13:93-103.

Brasier, C. M., and Buck, K. W. 2001. Rapid evolutionary changes in a globally invading fungal pathogen (Dutch elm disease). Biol. Invasions 3: 223-233.

Bryner, S. F., Sotirovski, K., Akilli, S., Risteski, M., Perlerou, C., and Rigling, D. 2013. Informative value of canker morphology on the presence or absence of virus infection in chestnut blight cankers. For. Pathol. 43:496-504.

Cortesi, P., and Milgroom, M. G. 1998. Genetics of vegetative incompatibility in Cryphonectria parasitica. Appl. Environ. Microbiol. 64:2988-2994.

Cortesi, P., Milgroom, M. G., and Bisiach, M. 1996. Distribution and diversity of vegetative compatibility types in subpopulations of Cryphonectria parasitica in Italy. Mycol. Res. 100:1087-1093.

Cortesi, P., Rigling, D., and Heiniger, U. 1998. Comparison of vegetative compatibility types in Italian and Swiss subpopulations of Cryphonectria parasitica. Eur. J. Forest Pathol. 28:167-176.

Davis, M. A. 2003. Biotic globalization: Does competition from introduced species threaten biodiversity? Bioscience 53:481-489.

Double, M., Kolp, M. R., Jarosz, A. M., Danvelos Baines, A., Fulbright, D. W., and MacDonald, W. L. 2013. Fungi associated with hypovirulent cankers of differing ages on American chestnut. Acta Hortic. 1043:57-65. 
Dutech, C., Fabreguettes, O., Capdevielle, X., and Robin, C. 2010. Multiple introductions of divergent genetic lineages in an invasive fungal pathogen, Cryphonectria parasitica, in France. Heredity 105:220-228.

Fisher, M. C., Henk, D. A., Briggs, C. J., Brownstein, J. S., Madoff, L. C., and McCraw, S. L. 2012. Emerging fungal threats to animal, plant and ecosystem health. Nature 484:186-194.

Grente, J. 1965. Les formes hypovirulentes d'Endothia parasitica et In espories de lutte contre le chancre du chataignier. C. R. Acad. Agric. Fr. 51:1033-1037.

Gross, A., Hosoya, T., and Queloz, V. 2014. Population structure of the invasive forest pathogen Hymenoscyphus pseudoalbidus. Mol. Ecol. 23: 2943-2960.

Guerin, L., Froidefond, G., and Xu, X.-M. 2001. Seasonal patterns of dispersal of ascospores of Cryphonectria parasitica (chestnut blight). Plant Pathol. 50:717-724.

Gurevitch, J., and Padilla, D. K. 2004. Are invasive species a major cause of extinctions? Trends Ecol. Evol. 19:470-474.

Hammer, Ø., Harper, D. A. T., and Ryan, P. D. 2001. Past: Paleontological statistical software package for educational and data analysis. Palaeontol. Electron. 4:1-9.

Hogan, E. P., and Griffin, G. J. 2002. Incomplete movement of Cryphonectria hypovirus 1 within a vegetative compatibility type of Cryphonectria parasitica in natural cankers on grafted American chestnut trees. For. Pathol. 32:331-344.

Houston, D. R. 1994. Temporal and spatial shift within the Nectria pathogen complex associated with beech bark disease of Fagus grandifolia. Can. J. For. Res. 24:960-968

Ježić, M., Krstin, L., Poljak, I., Liber, Z., Idžojtić, M., Jelić, M., Meštrović, J., Zebec, M., and Curković-Perica, M. 2014. Castanea sativa: Genotypedependent recovery from chestnut blight. Tree Genet. Genomes 10:101-110.

Ježić, M., Krstin, L., Rigling, D., and Curkovć-Perica, M. 2012. High diversity in populations of the introduced plant pathogen, Cryphonectria parasitica, due to encounters between genetically divergent genotypes. Mol. Ecol. 21: 87-99.

Krstin, L., Katanić, Z., Ježić, M., Poljak, I., Nuskern, L., Matković, I., Idžojtić, M., and Curković-Perica, M. 2016. Biological control of chestnut blight in Croatia: An interaction between host sweet chestnut, its pathogen Cryphonectria parasitica and the biocontrol agent Cryphonectria hypovirus 1. Pest Manage. Sci. 73:582-589.

Krstin, L., Novak-Agbaba, S., Rigling, D., and Ćurković-Perica, M. 2011. Diversity of vegetative compatibility types and mating types of Cryphonectria parasitica in Slovenia and occurrence of associated Cryphonectria hypovirus 1. Plant Pathol. 60:752-761.

Krstin, L., Novak-Agbaba, S., Rigling, D., Krajačić, M., and Ćurković Perica, M. 2008. Chestnut blight fungus in Croatia: Diversity of vegetative compatibility types, mating types and genetic variability of associated Cryphonectria hypovirus 1. Plant Pathol. 57:1086-1096.

Linde, C. C., Zhan, J., and McDonald, B. A. 2002. Population structure of Mycosphaerella graminicola: From lesions to continents. Phytopathology 92:946-955.

McDonald, B. A., and Linde, C. 2002. Pathogen population genetics, evolutionary potential, and durable resistance. Annu. Rev. Phytopathol. 40:349-379.

Milgroom, M. G., and Cortesi, P. 1999. Analysis of population structure of the chestnut blight fungus based on vegetative incompatibility genotypes. Proc. Natl. Acad. Sci. USA 96:10518-10523.
Milgroom, M. G., Sotirovski, K., Spica, D., Davis, J. E., Brewer, M. T., and Milev, M. 2008. Clonal population structure of the chestnut blight fungus in expanding ranges in southeastern Europe. Mol. Ecol. 17:4446-4458.

Mlinarec, J., Ježić, M., Ćosić, J., and Ćurković-Perica, M. 2017. Multilocus PCR assay reveals high diversity of vegetative compatibility types in populations of Cryphonectria parasitica in Croatia. Plant Pathol. 38:42-49.

Naegele, R. P., Kurjan, J. D., Saude, C., and Hausbeck, M. K. 2016. Regional and temporal population structure of Pseudoperonospora cubensis in Michigan and Ontario. Phytopathology 106:372-379.

Peever, T. L., Liu, Y.-C., Cortesi, P., and Milgroom, M. G. 2000. Variation in tolerance and virulence in the chestnut blight fungus-hypovirus interaction. Appl. Environ. Microbiol. 66:4863-4869.

Penczykowski, R. M., Laine, A. L., and Koskella, B. 2016. Understanding the ecology and evolution of host-parasite interactions across scales. Evol. Appl. 9:37-52.

Peters, F. S., Bußkamp, J., Prospero, S., Rigling, D., and Metzler, B. 2014. Genetic diversification of the chestnut blight fungus Cryphonectria parasitica and its associated hypovirus in Germany. Fungal Biol. 118:193-210.

Robin, C., Anziani, C., and Cortesi, P. 2000. Relationship between biological control, incidence of hypovirulence, and diversity of vegetative compatibility types of Cryphonectria parasitica in France. Phytopathology 90: 730-737.

Robin, C., and Heiniger, U. 2001. Chestnut blight in Europe: Diversity of Cryphonectria parasitica, hypovirulence and biocontrol. For. Snow Landsc. Res. 76:361-367.

Short, D. P. G., Double, M., Nuss, D. L., Stauder, C. M., MacDonald, W., and Kasson, M. T. 2015. Multilocus PCR assays elucidate vegetative incompatibility gene profiles of Cryphonectria parasitica in the United States. Appl. Environ. Microbiol. 81:5736-5742.

Solla, A., Dacasa, M. C., Nasmith, C., Hubbes, M., and Gil, L. 2008. Analysis of Spanish populations of Ophiostoma ulmi and O. novo-ulmi using phenotypic characteristics and RAPD markers. Plant Pathol. 57:33-44.

Springer, J. C., Baines, A. L. D., Fulbright, D. W., Chansler, M. T., and Jarosz, A. M. 2013. Hyperparasites influence population structure of the chestnut blight pathogen, Cryphonectria parasitica. Phytopathology 103:1280-1286.

Thach, T., Ali, S., De Vallavieille-Pope, C., Justesen, A. F., and Hovmøller, M. S. 2016. Worldwide population structure of the wheat rust fungus Puccinia striiformis in the past. Fungal Genet. Biol. 87:1-8.

Thrall, P. H., and Burdon, J. J. 2003. Evolution of virulence in a plant hostpathogen metapopulation. Science 299:1735-1737.

Trestić, T., Uščuplić, M., Colinas, C., Rolland, G., Giraud, A., and Robin, C. 2001. Vegetative compatibility type diversity of Cryphonectria parasitica populations in Bosnia-Herzegovina, Spain and France. For. Snow Landsc. Res. 76:391-396.

Trumbore, S., Brando, P., and Hartmann, H. 2015. Forest health and global change. Science 349:814-818.

Vainio, E. J., Mu, M. M., Korhonen, K., Piri, T., and Hantula, J. 2015. Viruses accumulate in aging infection centers of a fungal forest pathogen. ISME J. 9:497-507.

Van Alfen, N. K., Jaynes, R. A., Anagnostakis, S. L., and Day, P. R. 1975. Chestnut blight: Biological control by transmissible hypovirulence in Endothia parasitica. Science 189:890-891.

Zhang, L., Baasiri, R. A., and Van Alfen, N. K. 1998. Viral repression of fungal pheromone precursor gene expression. Mol. Cell. Biol. 18:953-959. 